\title{
Assessing Genetic Variability for Root Traits and Identification of Trait-Specific Germplasm in Chickpea Reference Set
}

\author{
N. Lalitha, Hari D. Upadhyaya,^ L. Krishnamurthy, J. Kashiwagi, P.B. Kavikishor, and S. Singh
}

\begin{abstract}
Chickpea (Cicer arietinum L.) is a major grain legume cultivated largely on residual soil moisture in the arid and semiarid regions of the world. Terminal drought stress is one of the major causes of yield loss, and a deep root system has been recognized as one of the most important traits for enhancing drought adaptability. To diversify the current genetic base of root traits, the present study explored the variation for root traits in the reference set of chickpea $(n=300)$ germplasm. Genetic variability for root traits at $35 \mathrm{~d}$ after sowing was assessed using a polyvinyl chloride (PVC) cylinder culture system in two postrainy seasons. Largest genetic variability was observed for dry weights of shoot (broad-sense heritability $\left.\left[h^{2}\right]=0.69-0.74\right)$ and root $\left(h^{2}=0.52-0.70\right)$. For root-length density $\left(h^{2}=0.42-0.43\right)$ and root/ total-plant dry-weight ratio $\left(h^{2}=0.32-0.54\right)$, $h^{2}$ values were moderate but the variation was large, indicating scope for selection. The performance of the reference set accessions was identified for each of key traits. Accessions with the best root-length densities along with root and shoot dry weights were found to originate from the Mediterranean region and western Asia emphasizing the importance of whole collection from these regions for superior root traits. This study identified 23 new accessions for widening the parental base in further drought tolerance breeding efforts and identified superior traits in already adapted genetic backgrounds.
\end{abstract}

N. Lalitha, Hari D. Upadhyaya, L. Krishnamurthy, J. Kashiwagi, and S. Singh, International Crops Research Institute for the Semi-Arid Tropics (ICRISAT), Patancheru 502 324, Telangana, India; Hari D. Upadhyaya, Dep. of Agronomy, Kansas State Univ., Manhattan, KS 66506 and UWA Institute of Agriculture, Univ. of Western Australia, Crawley, WA 6009, Australia; P.B. Kavikishor, Osmania Univ., Hyderabad, Telangana, India. Received 30 Dec. 2014. Accepted 6 May 2015. ^Corresponding author (h.upadhyaya@cgiar.org).

Abbreviations: BGM, Botrytis gray mold; DAS, days after sowing; G $\times$ E, genotype $\times$ environment interaction; $h^{2}$, broad-sense heritability; PVC, polyvinyl chloride; QTL, quantitative trait loci; REML, residual (or restricted) maximum likelihood.

\footnotetext{
Chickpea is the third most important legume crop worldwide (FAOSTAT, 2013), cultivated mostly in the arid and semiarid regions of the world. It is a self-pollinated (van der Maesen, 1987), diploid member of the Leguminosae family with basic chromosome number eight and genome size of $738 \mathrm{Mb}$. Chickpea is a rich source of protein, essential amino acids, and vitamins such as riboflavin, niacin, thiamin, folate, and vitamin A precursor $\beta$-carotene (Jukanti et al., 2012). Southern Asia is the major producer of chickpea, contributing approximately $72 \%$ of the production. Chickpea is well adapted to grow on residual soil moisture because of its prolific and deep root characteristics; hence, it has advantages over other post-rainy-season crops (Yusuf Ali et al., 2002). Globally, chickpea is produced in 55 countries, and 24 of these countries produce $>10,000$ t. Chickpea productivity has been shown to vary among countries, for example, from $3.5 \mathrm{t} \mathrm{ha}^{-1}$ in Israel to $0.25 \mathrm{t} \mathrm{ha}^{-1}$ in Kenya.
}

\footnotetext{
Published in Crop Sci. 55:1-12 (2015).

doi: 10.2135/cropsci2014.12.0847

(C) Crop Science Society of America | 5585 Guilford Rd., Madison, WI 53711 USA

All rights reserved. No part of this periodical may be reproduced or transmitted in any form or by any means, electronic or mechanical, including photocopying, recording, or any information storage and retrieval system, without permission in writing from the publisher. Permission for printing and for reprinting the material contained herein has been obtained by the publisher.
} 
Terminal drought stress is the major constraint threatening yield stability in arid and semiarid regions of the world (Krishnamurthy et al., 2010) and continues to have significant impacts in both developed and developing countries. This problem will be exacerbated by climate change, resulting in increased incidence and severity of drought in many regions and thereby reducing food production. Drought tolerance is a generic term for a highly complex phenomenon of plant responses (Serraj and Sinclair, 2002). Tolerance to drought is quantitative in nature and the underlying mechanism can vary, that is, drought escape, avoidance, and tolerance. Worldwide, the loss in chickpea production resulting from drought stress alone is estimated to be in the range of 40 to $50 \%$ (Ahmad et al., 2005). The predicted climate change scenario and the ever-increasing population pressure impose an urgent need for developing stable varieties with an enhanced water acquisition through improved root traits that could have a significant impact on global food security. The development of crop cultivars with enhanced drought adaptation and yield stability has been the focus of many crop improvement programs.

Ninety percent of the world's chickpea is grown rainfed (Kumar and Abbo, 2001), where terminal drought is one of the major constraints for grain yield. Chickpea yields are highly prone to large genotype $\times$ environment interactions $(\mathrm{G} \times \mathrm{E})$ in marginal environments (Kashiwagi et al., 2008). Breeding for yield under drought conditions using conventional approaches has not been quite successful over the years because of instability and poor heritability of yield. Genotypic variation for root traits and their functional implications for water acquisition and increased yields under water-limited conditions have been well documented in many crops (Ludlow and Muchow, 1990; Saxena and Johansen, 1990; Turner et al., 2001; Kashiwagi et al., 2006). Therefore, it is important to understand the genetic variability in water uptake and the root traits that confer drought avoidance. Among the root traits, rooting depth, root biomass, and root-length density have been identified as the major promising traits for terminal drought tolerance, as these help in greater extraction of soil water (Kashiwagi et al., 2006).

Roots are the first line of defense to respond to drought stress, flooding, temperature extremes, or nutrient limitations and are often viewed as the key to solving drought stress related issues. In terms of root architecture, more prolific root systems extracting more water from upper soil layers and deeper root systems extracting soil moisture from deeper soil layers are important for maintaining yield under terminal drought (Turner et al., 2001; Lynch, 2013). In general, cultivated field crops have root depths that indeed do not extend much beyond $1 \mathrm{~m}$ (Kutschera et al., 2009), which implies that there is an intense scope to breed for these traits (Kell, 2011). The development of an efficient root system better adapted to different soil conditions is crucial for the success in productivity under stress. Breeding for enhanced yield stability and potential under drought stress has been quite successful in some crops (Serraj et al., 2003; Kell, 2011; Comas et al., 2013).

Several physiological, morphological, and phenological traits may play a significant role in crop adaptation to drought stress during soil drying (Serraj et al., 2004). Root traits play a major role in drought tolerance under terminal drought environments. However, root traits can have a major influence on yield only when root-mediated water absorption becomes the major limitation under drought stress. Contribution of root traits to drought tolerance, particularly in chickpea, has been well established (Singh et al., 1995; Soltani et al., 1999, 2000; Kashiwagi et al., 2006, 2015; Varshney et al., 2014). Equipping chickpea with stress-tolerant traits is important, as this crop is largely cultivated in marginal environments prone to many kinds of abiotic stresses limiting the productivity. Such efforts to equip chickpeas with drought avoidance traits, including root traits, have been shown to be successful in improving the yield stability in peninsular India (Varshney et al., 2014). At this stage of breeding progress, the current study in search of potential genetic variation that is much wider and diverse for the roots traits becomes important.

The breeding for large root biomass and deep-root system that has been performed since the 1990s, particularly at the International Crops Research Institute for the Semi-Arid Tropics (ICRISAT), India, in a predominantly stored-soil-moisture growing environment, and the International Center for Agricultural Research in the Dry Areas (ICARDA) in the Mediterranean with an in-season rainfall environment, has resulted in the identification of chickpea germplasm superior for root traits by 30\% (Serraj et al., 2004; Kashiwagi et al., 2005, 2006). A subsequent marker-assisted breeding for these traits by incorporating the quantitative trait loci (QTL), well associated with root and other drought avoidance related traits, has facilitated identification of progenies with a $30 \%$ yield advantage in multilocation drought environments (Varshney et al., 2014). This success encourages further diversification of parental base for use in subsequent breeding efforts catering the needs of vast chickpea growing agroecological environments. The molecular-marker-based reference set of chickpea germplasm (Upadhyaya et al., 2008) has been considered as an ideal set for this exploration, as research to date suggests that mini core collection (Upadhyaya and Ortiz, 2001) and genotype-based reference sets (Glaszmann et al., 2010) were highly useful in extracting germplasm with beneficial agronomic, physiological, and nutritional traits for use in crop improvement programs involving resistance to abiotic and biotic stresses (Krishnamurthy et al., 2013a,b; Upadhyaya et al., 2013). With an objective to understand the genetic variation for root traits 


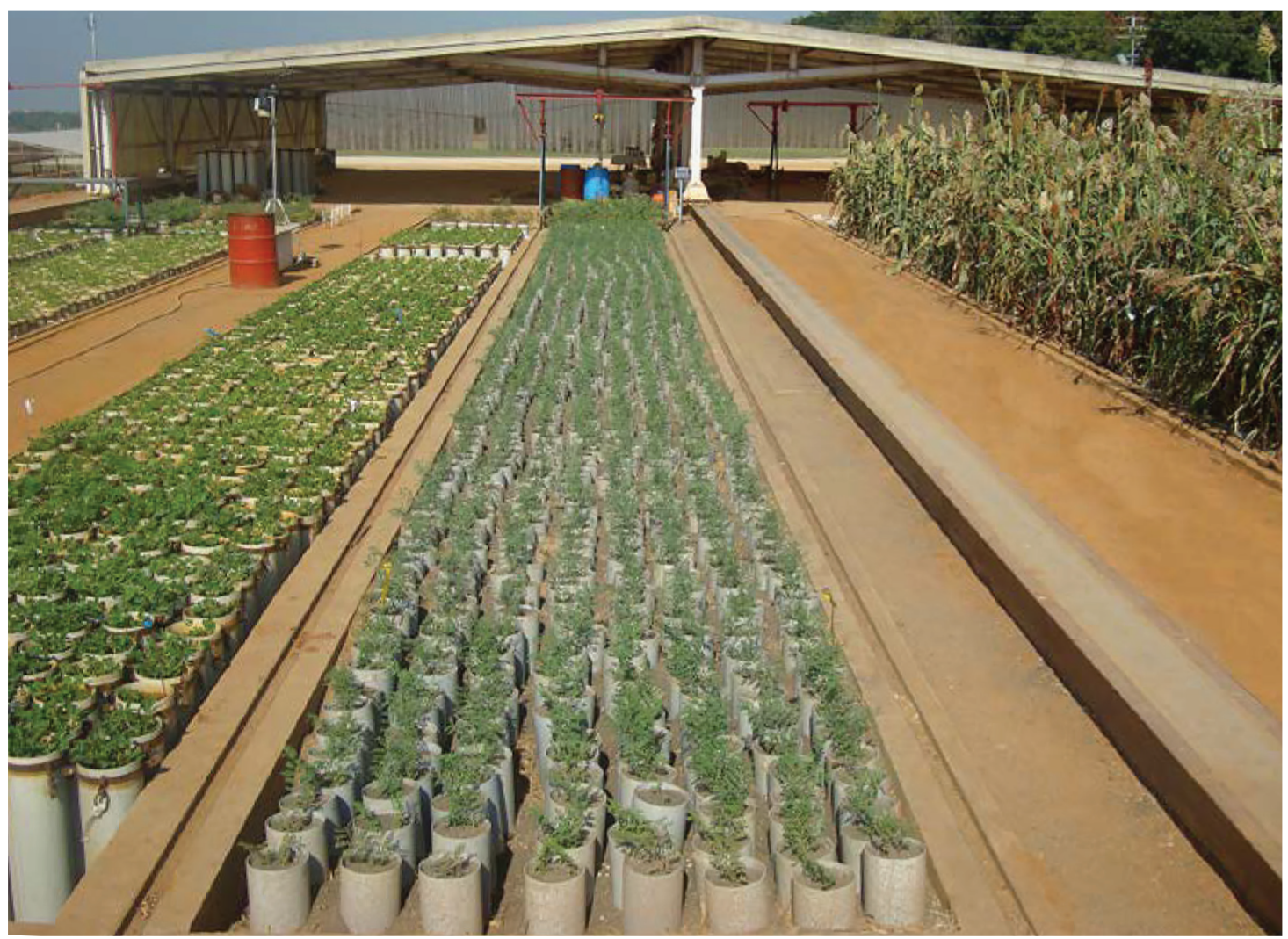

Figure 1. Three hundred accessions of chickpea reference set germplasm (at the center) being grown in a PVC cylinder culture system for phenotyping the drought-avoidance root traits. At the background is a parked rain-out shelter that would move on top of the experiment at the incidence of rain.

and to select a large number of diverse germplasm accessions, this study undertakes extensive phenotyping of the chickpea reference set for the root traits.

\section{MATERIALS AND METHODS}

Three hundred chickpea genotypes were selected for this study, which includes 293 accessions from C. arietinum, four from C. reticulatum Ladiz., and three from C. echinospermum P. H. Davis along with six control cultivars (ICC 4958, Annigeri, ICCV 10, G 130, L 550, and KAK 2) planted in PVC cylinder culture system under a rainout shelter during two consecutive postrainy seasons (2007-2008 and 2008-2009, hereafter referred to as 2007 and 2008, respectively) at ICRISAT Center, Patancheru $\left(17^{\circ} 27^{\prime} \mathrm{N}, 78^{\circ} 28^{\prime} \mathrm{E}, 545 \mathrm{~m}\right.$ asl). ICC 4958 is a desi, drought-resistant, short-duration, and high-yielding cultivar under terminal drought with 30\% more root weight than the best-adapted cultivar Annigeri (Krishnamurthy et al., 1996). Annigeri, G 130, L 550 (Saxena and Singh, 1987), ICCV 10 (Gowda et al., 1995), and KAK 2 (Zope et al., 2002) are varieties widely grown in India (Dua et al., 2001). Annigeri, ICCV 10, and G 130 are early-, medium-, and late-maturing desi cultivars, respectively. KAK 2 and L 550 are short-duration and long-duration kabuli cultivars, respectively.

The chickpea reference set was grown in 18-cm-diam. by 120-cm-tall PVC cylinders following Kashiwagi et al. (2005) under a rainout shelter in an $\alpha$-design in three replications. The cylinders were placed in 1.2-m-deep cement pits to avoid the incidence of direct solar radiation on the cylinders. The cylinders, except the top $15 \mathrm{~cm}$, were filled with an equimixture (w/w) of Vertisol and sand mixed with di-ammonium phosphate at a rate of $0.07 \mathrm{~g} \mathrm{~kg}^{-1}$. The water content of the soil mixture was equilibrated to $70 \%$ field capacity using a concrete mixer to create the conditions similar to those in the field at sowing time. The sand was mixed to balance the bulk density and to reduce the water holding capacity. The top $15 \mathrm{~cm}$ of the cylinder was filled with the same soil-sand mixture but dry. Four seeds of each genotype were sown in each cylinder. The cylinders were irrigated with $1 \mathrm{~L}$ of water at the time of sowing, $150 \mathrm{~mL}$ of water three times on alternate days until seedlings uniformly emerged, and then no more irrigation was applied until harvest. Immediately after sowing, all cylinders were supplied with a rhizobial inoculum (Mesorhizobium ciceri, strain IC 59) as a water suspension. Two healthy representative plants per cylinder were retained per cylinder at 7 days after sowing (DAS). The plants were grown under field conditions and protected from rainfall using a rainout shelter only when rains were expected (Fig. 1).

Plants were harvested at 35 DAS. After harvesting, the shoots were separated from roots and put into paper bags for assessing dry weights. The cylinders were then placed horizontally on a raised platform and the sand-soil mixture was washed gently with the help of running water. The root system and broken fine roots $(<5 \%)$ were placed on a sieve $(400 \mu \mathrm{m})$ and further washed free of soil. After completely removing the soil particles, the entire root system of each plant was placed in large polybags for transportation to the laboratory for measurement. Then the roots were stretched to measure their length as an estimate of rooting depth. The root system was then separated in to $30-\mathrm{cm}$ sections $(0-30,30-60,60-90$, and $90-120 \mathrm{~cm})$ to 
measure the root length at each of the 30-cm depths using an image analysis system (WinRhizo, Regent Instruments Inc.). Root-length density for each 30-cm soil horizon was obtained by dividing the root length by soil volume of a 30-cm section of the cylinder. However, for this presentation all the depth-wise root length was pooled and divided by the total soil volume concerning the specific rooting depth in each specific cylinder. The root and shoot dry weights were recorded after drying in a hotair oven at $80^{\circ} \mathrm{C}$ for $72 \mathrm{~h}$. Total-plant dry weight is sum of root and shoots dry weights. Root/total-plant dry-weight ratio was calculated as an indicator of biomass allocation to roots on dry weight basis. In addition, the indicator for the effectiveness of roots in shoot production was calculated by shoot-dry-weight/ root-length density ratio and leaf-area/root-length density.

The data for the root traits, rooting depth, root dry weight, root length, root volume, root surface area, and shoot dry weight were measured, and from this data total-plant dry weight, root-length density, root/total-plant dry-weight ratio, shoot dry-weight/root-length density, and leaf-area/root-length density, were estimated. These data were analyzed using residual (or restricted) maximum likelihood (REML) (Patterson and Thompson, 1971) in GenStat 14.1 software (VSN International, 2011). The replication-wise values of various traits in each year were used for statistical analysis using REML considering germplasm accessions $(G)$ as random. Variance components of accessions $\left(\sigma_{\mathrm{g}}^{2}\right)$ and error $\left(\sigma^{2}{ }_{\mathrm{e}}\right)$ and their standard errors (SE) were determined. Best linear unbiased predictors for the germplasm accessions were calculated for each trait and year separately. For pooled REML analysis, $G$ was considered random and season or year $(\mathrm{E})$ as fixed. The variance due to germplasm accessions $\left(\sigma_{\mathrm{g}}^{2}\right), \mathrm{G} \times \mathrm{E}$, and their standard errors were determined. The significance of the fixed effect of the season was assessed using the Wald (1943) statistic that asymptotically follows a $\chi^{2}$ distribution. Best linear unbiased predictors based on the analysis of individual seasons were used for further analysis. Phenotypic correlations among all the traits were calculated for each environment and for pooled data. The 35-d growing period was converted to thermal time using temperature observations recorded in the meteorological observatory of ICRISAT, Patancheru. Base temperature $\left(t_{\underline{b}}\right)$ was taken as $0^{\circ} \mathrm{C}$ and the equation used for calculating thermal time $\left({ }^{\circ} \mathrm{Cd}\right)$ was as follows:

$$
{ }^{\circ} \mathrm{Cd}=\sum_{\mathrm{t}=0}^{\mathrm{n}}\left(\frac{t_{\max }+t_{\min }}{2}-t_{\mathrm{b}}\right) .
$$

\section{RESULTS}

The REML analysis for all the seven root traits (shoot dry weight, root dry weight, rooting depth, root/total-plant dry-weight ratio, root-length density, root surface area, and root volume) each year showed the existence of highly significant genetic variation among accessions. In pooled analysis, genotypic variation $\left(\sigma_{\mathrm{g}}^{2}\right)$ and $\mathrm{G} \times \mathrm{E}$ were significant for all the traits. Wald statistics had revealed that all the traits varied significantly across the years. Therefore, the means for the individual years were considered separately. The error components noticed across the years for the traits, shoot dry weight, root dry weight, root-length density, root surface area, and root volume were heterogeneous, and, therefore, it was necessary to draw inferences separately across years. However, the total components of variation due to replications never exceeded $20 \%$ for all the variables across years.

The chickpea reference set exhibited a large genotypic variability for the shoot dry weight in both the seasons. It ranged from 1.34 to $2.77 \mathrm{~g}$ in 2007 and from 1.10 to $2.41 \mathrm{~g}$ in 2008 (Table 1; Fig. 2a) and had the highest $h^{2}$ of 0.69 and 0.74 , respectively, in both the seasons. Root dry weight also exhibited a large range of variation, from 0.47 to $0.79 \mathrm{~g}$ with a $h^{2}$ of 0.52 in 2007 and 0.39 to $0.89 \mathrm{~g}$ with a $h^{2}$ of 0.70 in 2008 (Fig. 2b). The accessions varied significantly for the rooting depth with a range of 89.40 to $137.13 \mathrm{~cm}$ in 2007 and from 85.50 to $146.02 \mathrm{~cm}$ in 2008 (Fig. 2c). This interaction of root dry weight with rooting depth is likely due to the specific limiting conditions of soil water in cylinders: first, the soil moisture with which the experiment started was only $70 \%$ of field capacity; and second, the complete utilization of soil water until $45-\mathrm{cm}$ depth by 35 DAS leading to a likely simultaneous sloughing of the surface soil roots, encouraging continuance of root growth in the deeper wet zones. Therefore, as far as the field conditions are concerned, it is also likely that the desirable deep-root variability for mining the deeper soil layers originates right at this stage.

Root/total-plant dry-weight ratio showed a large genotypic variability ranging from 22.10 to $27.81 \%$ in 2007 and 20.90 to $35.05 \%$ in 2008 (Table 1; Fig. 2d) with a $h^{2}$ of 0.32 and 0.54 in 2007 and 2008, respectively, whereas, for root-length density, it ranged from 0.14 to $0.27 \mathrm{~cm} \mathrm{~cm}^{-3}$ in 2007 and from 0.18 to $0.29 \mathrm{~cm} \mathrm{~cm}^{-3}$ in 2008 (Table 1; Fig. 2e) with a mean $h^{2}$ of 0.43 . Root surface area ranged from 565.6 to $930.4 \mathrm{~cm}^{2}$ in 2007 and 629.6 to $1003.9 \mathrm{~cm}^{2}$ in 2008, and the root volume ranged from 6.76 to 13.75 $\mathrm{cm}^{3}$ in 2007 and 8.55 to $15.85 \mathrm{~cm}^{3}$ in 2008 (Table 1). Both the root surface area and root volume are expected to exhibit the same pattern and trend of variation as these are estimated as proportionate values of root length and diameter. Shoot dry weight/root-length density ratio also exhibited a large range of variation, from 8.5 to $14.3 \mathrm{~cm}$ $\mathrm{cm}^{-3}$ in 2007 and 5.8 to $11.0 \mathrm{~cm} \mathrm{~cm}^{-3}$ in 2008, with a moderate level of $h^{2}(0.43)$ (data not shown), indicating that the genotypic variation with relatively greater root strength is available to cope with varying levels of soil drying as experienced both under irrigated and rainfed cropping systems. Leaf area to root-length density ranged from 28.6 to 128.9 in chickpea reference set accessions, among them, 13 (28.6-38.2) accessions were found to be superior to the best control cultivar (data not shown).

Compared with 2008, the means for shoot dry weight had been marginally greater in 2007 (first year), whereas all the root traits such as rooting depth, root dry weight, root-length density, root/total weight ratio, root surface 
Table 1. Root traits in 300 accessions of the chickpea reference set evaluated in PVC cylinders under receding soil moisture condition in a Vertisol during the 2007 to 2008 and 2008 to 2009 postrainy seasons, ICRISAT, Patancheru, India.

\begin{tabular}{|c|c|c|c|c|c|}
\hline $\begin{array}{c}\text { Root trait } \\
\text { and season }\end{array}$ & Trial mean & $\begin{array}{c}\text { Range of } \\
\text { predicted means }\end{array}$ & $\sigma_{g}^{2}$ & SE & Heritability $\left(h^{2}\right)$ \\
\hline \multicolumn{6}{|l|}{ Shoot dry weight (g) } \\
\hline 2007-2008 & 1.89 & $1.34-2.77$ & $0.097^{\star *}$ & 0.0119 & 0.69 \\
\hline 2008-2009 & 1.65 & $1.10-2.41$ & $0.081^{\star \star}$ & 0.0092 & 0.74 \\
\hline \multicolumn{6}{|l|}{ Root dry weight (g) } \\
\hline 2007-2008 & 0.63 & $0.47-0.79$ & $0.007^{\star \star}$ & 0.0011 & 0.52 \\
\hline 2008-2009 & 0.64 & $0.39-0.89$ & $0.013^{\star *}$ & 0.0015 & 0.70 \\
\hline \multicolumn{6}{|l|}{ Rooting depth (cm) } \\
\hline 2007-2008 & 113.27 & $89.40-137.13$ & $27.3^{\star *}$ & 7.7 & 0.32 \\
\hline 2008-2009 & 115.76 & $85.50-146.02$ & $26.6^{\star *}$ & 7.4 & 0.33 \\
\hline \multicolumn{6}{|c|}{ Root/total-plant dry-weight ratio (\%) } \\
\hline 2007-2008 & 24.40 & $22.10-27.81$ & $2.89^{* \star}$ & 0.83 & 0.32 \\
\hline 2008-2009 & 25.97 & $20.90-35.05$ & $5.91^{\star *}$ & 0.95 & 0.54 \\
\hline \multicolumn{6}{|c|}{ Root-length density $\left(\mathrm{cm} \mathrm{cm}^{-3}\right)$} \\
\hline 2007-2008 & 0.21 & $0.14-0.27$ & $0.0003^{\star *}$ & 0.00006 & 0.43 \\
\hline 2008-2009 & 0.24 & $0.18-0.29$ & $0.0003^{\star *}$ & 0.00009 & 0.42 \\
\hline \multicolumn{6}{|c|}{ Root surface area $\left(\mathrm{cm}^{2}\right)$} \\
\hline 2007-2008 & 748.7 & 565.6-930.4 & $9,360^{* *}$ & 2072 & 0.40 \\
\hline 2008-2009 & 803.0 & $629.6-1003.9$ & $11,971^{\text {** }}$ & 2292 & 0.46 \\
\hline \multicolumn{6}{|l|}{ Root volume $\left(\mathrm{cm}^{3}\right)$} \\
\hline 2007-2008 & 9.32 & $6.76-13.75$ & $2.69^{\star \star}$ & 0.54 & 0.44 \\
\hline 2008-2009 & 11.70 & $8.55-15.85$ & $3.91^{* *}$ & 0.74 & 0.47 \\
\hline
\end{tabular}

** Significant at the 0.01 probability level.

area, and root volume traits were marginally greater in 2008. This selective enhancement of growth in roots or shoots is likely to be governed by the variation in higher daily mean air temperature experienced and the growing degree-days taken in 2008 repetition experiment. The first year was relatively cooler, with a daily mean air temperature of $21.0^{\circ} \mathrm{C}$ and an accrual of 741 growing degreedays compared with second year with a daily mean air temperature of $23.0^{\circ} \mathrm{C}$ and an accrual of 804 growing degree-days. In the cooler first year, the shoot growth, and the rooting depth were more favored, whereas in the warmer second year all the root parameters were more favored. The $h^{2}$ values were greater in the second year for all the traits except for the root-length density.

Most of the correlations between traits revealed the existence of highly significant $(p<0.01)$ associations in both the years (Table 2). The correlation coefficients have ranged from -0.57 to 0.98 in 2007 while it was -0.28 to 0.97 in 2008. The closeness of the correlations demonstrated that the associations observed were comparable between the seasons. Root dry weight, total-plant dry weight, root-length density, and root surface area were closely and positively correlated with shoot dry weight in both the years (Table 2), indicating that approximate estimations of root traits are a possibility through shoot dry weight.

In the chickpea reference set, the number of accessions included was 35\% accessions from southern and Southeast Asia (105); 31\% from western Asia (93); 18.7\% from Mediterranean region (56); 7\% from Africa (21); $2.0 \%$ each from North America (6), the Russian Federation, and accessions with no information on biological status; 1.3\% from South America (4); and 1.0\% from Europe (3). This compared favorably with the number of accessions in the composite collection (Upadhyaya et al., 2006), as 39\% originates from southern and Southeast Asia, 25\% from western Asia, and 22\% from the Mediterranean region; Africa and the Americas each contributed 5\% of the collection. In the present study, germplasm that originated from the Mediterranean region and western Asia had significantly larger root-length density and root and shoot dry weight than other regions. A significant range of variation in the mean root-length density was noted among the regions (Fig. 3). Largely, accessions from the western Asian region were superior for rooting depth, from the Mediterranean region for root-length density and totalplant dry weight, and from the southern and Southeast Asia regions for root/total-plant dry-weight ratio (Table $3)$. When observed for the trait leaf area to root-length density, superior accessions were observed from the southern and Southeast Asia and African regions. Root traits and total leaf area are significantly correlated with total biomass, indicating the strong dependence of these traits on overall growth rates (data not shown).

The accession ICC 4958 is currently being used as a major donor for superior root and shoot traits in drought tolerance breeding. In this study, there were 78 accessions in 2007 with a shoot weight of 2.07 to $2.77 \mathrm{~g}$ (ICC 4958, $1.86 \pm 0.38$ ) and 80 in 2008 with a shoot weight of 1.87 


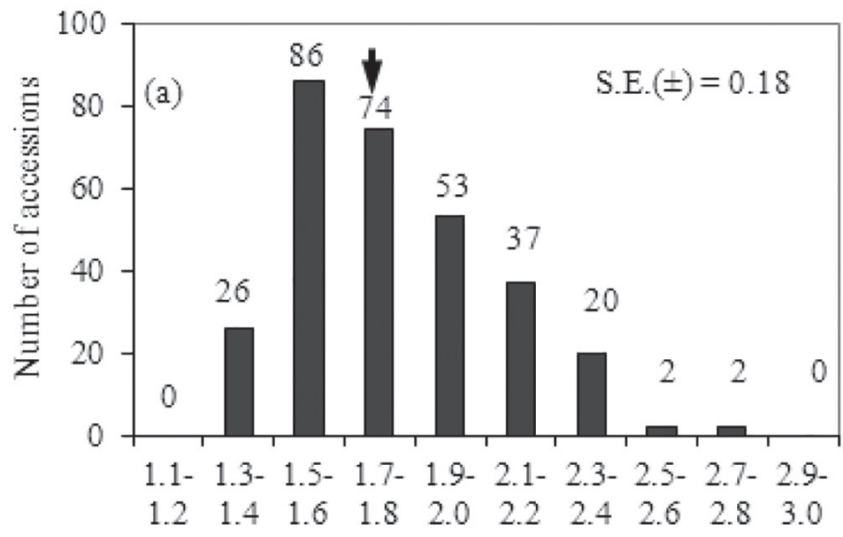

Shoot dry weight range (g)
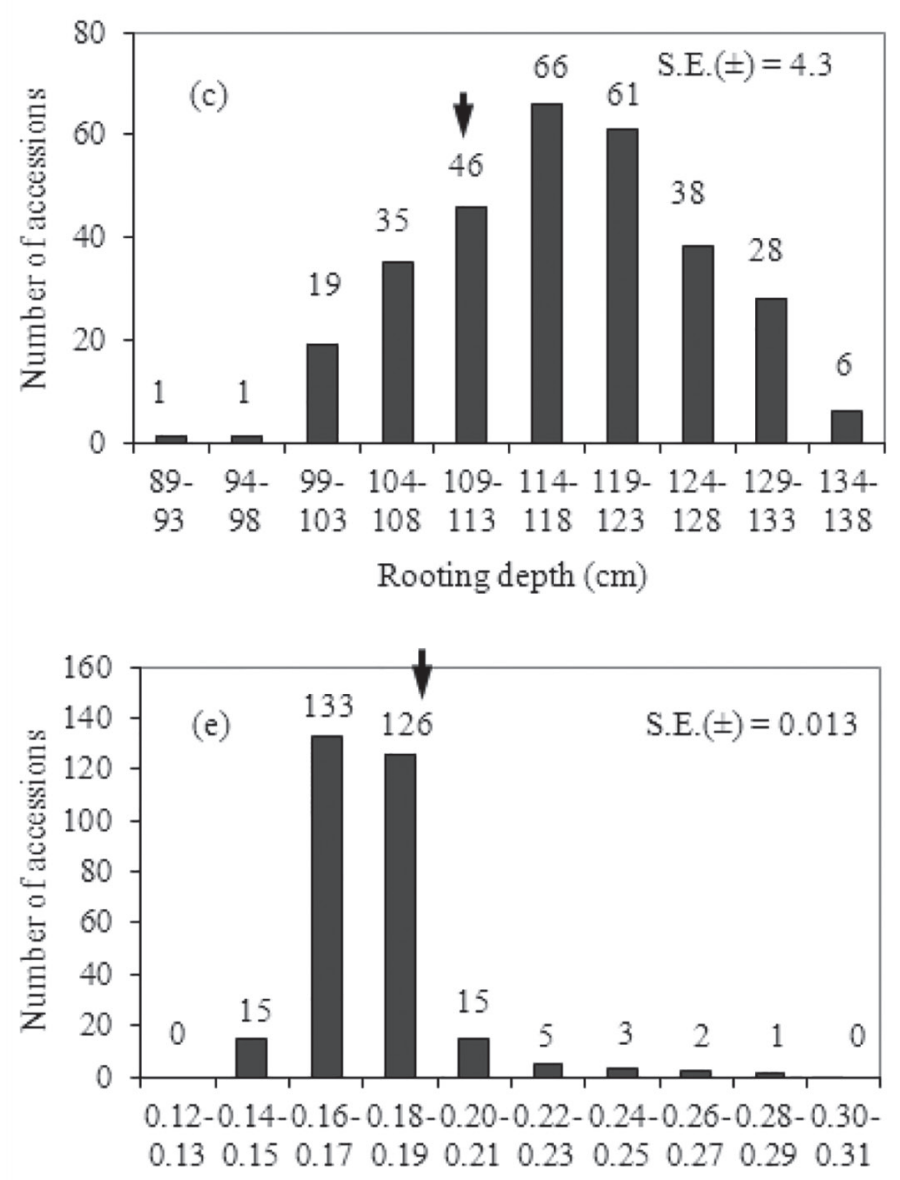

Root length density $(\mathrm{cm} \mathrm{cm}-3)$
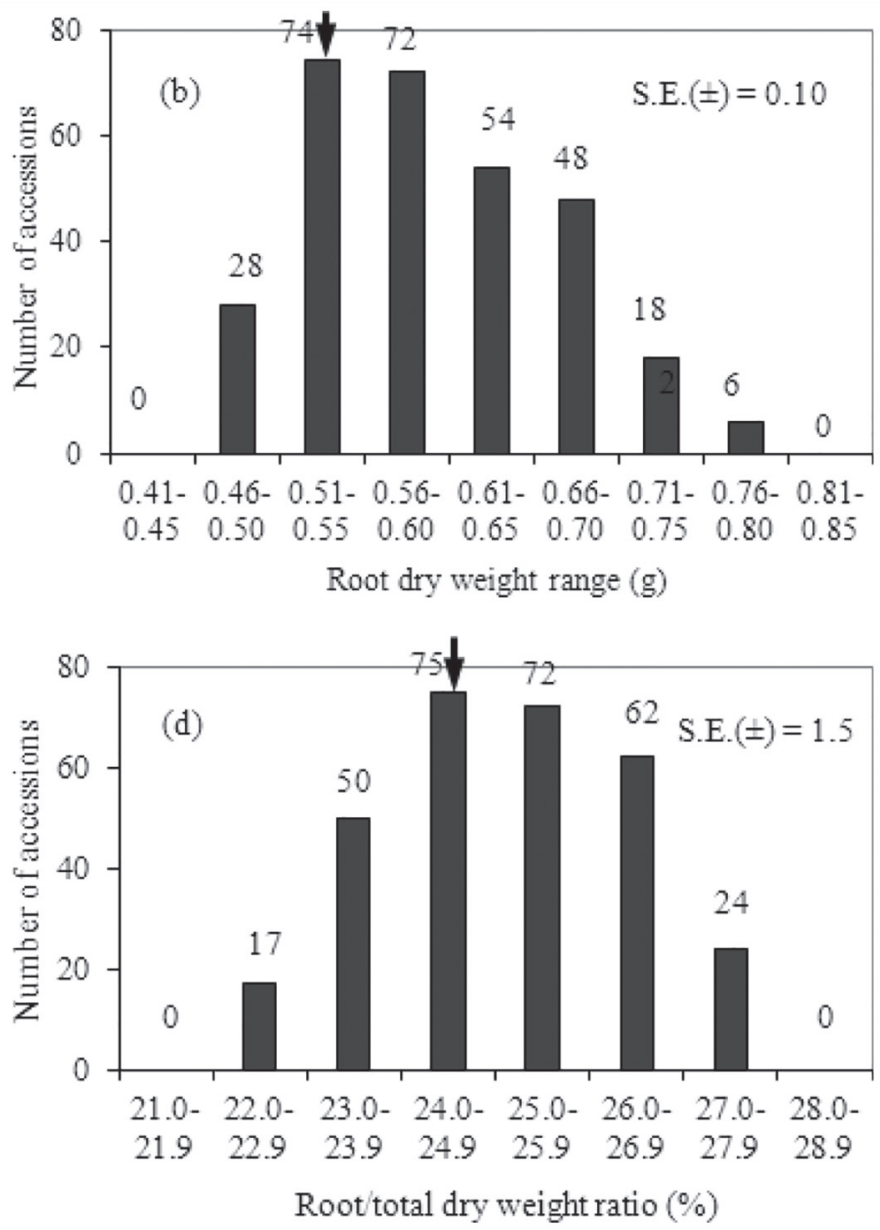

Figure 2. Distribution of reference set accessions in 2007 to 2008 at 35 days after sowing: (a) shoot dry weight (g), (b) Root dry weight (g), (c) rooting depth (cm), (d) Root/total-plant dry-weight ratio (\%), (e) root-length density $\left(\mathrm{cm} \mathrm{cm}^{-3}\right)$.

to $2.41 \mathrm{~g}$ that were significantly superior to ICC 4958 (1.52 \pm 0.31) for shoot weight. Similarly, for root dry weight there were 60 accessions in 2007 with a weight of 0.66 to $0.79 \mathrm{~g}$ (ICC $4958,0.57 \pm 0.14$ ) and 72 in 2008 with a weight of 0.65 to $0.89 \mathrm{~g}$ that were better than ICC 4958 $(0.53 \pm 0.15)$. For rooting depth, there were 19 accessions in 2007 with a rooting depth of 112.31 to $137.13 \mathrm{~cm}$ (ICC 4958, $108.52 \pm 10.93$ ) and 21 in 2008 with a rooting depth of 111.90 to $146.02 \mathrm{~cm}$ that were better than ICC
$4958(111.10 \pm 10.73)$. For root-length density, 16 accessions with a density of 0.22 to $0.27 \mathrm{~cm} \mathrm{~cm}^{-3}$ in 2007 (ICC $4958,0.20 \pm 0.04$ ) and 26 with a density of 0.22 to 0.29 $\mathrm{cm} \mathrm{cm}^{-3}$ in 2008 that were better than ICC $4958(0.24 \pm$ 0.04). For root surface area, 34 accessions having an area of 826.9 to $930.4 \mathrm{~cm}^{2}$ in 2007 (ICC 4958, $696.6 \pm 150.3$ ) and 48 having an area of 883.8 to $1003.9 \mathrm{~cm}^{2}$ in 2008 were found to be better than ICC $4958(773.5 \pm 153.1)$. And for the root volume, 37 accessions with a volume of 11.70 to 
Table 2. Correlation coefficients between various root traits of the chickpea reference set accessions sampled at 35 days after sowing (DAS) grown in PVC cylinders in two seasons. The correlations appearing diagonally at the bottom are for $2007-2008$ season and at the top are for 2008-2009 season.

\begin{tabular}{|c|c|c|c|c|c|c|c|c|c|c|}
\hline Trait $^{\dagger}$ & SDW & RDW & RDp & $\mathrm{R} / \mathrm{T}$ & TDWT & RL & RLD & RSA & RV & S/RLD \\
\hline SDW & & $0.706^{\star \star}$ & $0.246^{* \star}$ & $-0.201^{\star \star}$ & $0.974^{\star \star}$ & $0.529^{\star \star}$ & $0.589^{\star \star}$ & $0.652^{\star \star}$ & $0.591^{\star \star}$ & $0.939^{\star \star}$ \\
\hline RDW & $0.657^{* *}$ & & $0.408^{\star *}$ & $0.535^{\star \star}$ & $0.845^{\star *}$ & $0.608^{\star *}$ & $0.573^{\star *}$ & $0.811^{\star *}$ & $0.798^{* *}$ & $0.595^{\star *}$ \\
\hline $\mathrm{RDp}$ & $0.300^{\star \star}$ & $0.481^{\star \star}$ & & $0.237^{\star \star}$ & $0.325^{\star \star}$ & $0.688^{\star \star}$ & 0.065 & $0.464^{\star \star}$ & $0.399^{\star \star \star}$ & $0.290^{\star \star}$ \\
\hline $\mathrm{R} / \mathrm{T}$ & $-0.452^{\star \star}$ & $0.342^{\star \star}$ & $0.195^{\star \star}$ & & 0.018 & $0.196^{\star *}$ & 0.100 & $0.346^{\star \star}$ & $0.394^{\star \star}$ & $-0.284^{\star *}$ \\
\hline TDWT & $0.981^{\star *}$ & $0.784^{\star *}$ & $0.363^{\star * *}$ & $-0.287^{\star \star}$ & & $0.590^{* *}$ & $0.624^{\star *}$ & $0.747^{\star *}$ & $0.698^{* *}$ & $0.892^{\star *}$ \\
\hline $\mathrm{RL}$ & $0.535^{\star \star}$ & $0.620^{\star \star}$ & $0.738^{\star \star}$ & 0.057 & $0.592^{\star \star}$ & & $0.390^{\star \star}$ & $0.615^{\star \star}$ & $0.499^{\star \star}$ & $0.470^{\star *}$ \\
\hline RLD & $0.605^{\star \star}$ & $0.651^{\star *}$ & $0.310^{* *}$ & 0.001 & $0.657^{\star *}$ & $0.606^{\star \star}$ & & $0.773^{\star *}$ & $0.649^{\star \star}$ & $0.277^{\text {** }}$ \\
\hline RSA & $0.588^{\star \star}$ & $0.820^{\star *}$ & $0.525^{\star \star}$ & $0.225^{\star \star}$ & $0.686^{\star \star}$ & $0.711^{\star *}$ & $0.786^{\star *}$ & & $0.943^{\star \star}$ & $0.448^{\text {** }}$ \\
\hline $\mathrm{RV}$ & $0.476^{\star \star}$ & $0.772^{\star \star}$ & $0.435^{\star \star}$ & $0.289^{\star \star}$ & $0.582^{\star \star}$ & $0.551^{\star \star}$ & $0.670^{\star *}$ & $0.923^{\star \star}$ & & $0.425^{\star \star}$ \\
\hline S/RLD & $0.859^{\star *}$ & $0.403^{\star \star}$ & $0.176^{\star \star}$ & $-0.569^{\star \star}$ & $0.804^{\star \star}$ & $0.281^{\star *}$ & 0.117 & $0.232^{\star \star}$ & $0.168^{\star \star}$ & \\
\hline
\end{tabular}

** Correlation coefficients above 0.148 or below -0.148 are significant at the 0.01 probability level.

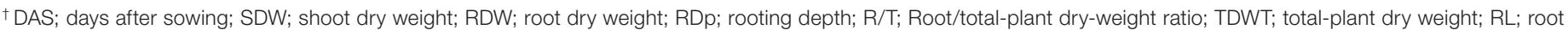
length; RLD; root-length density; RSA; root surface area; RV; root volume; S/RLD; shoot/root length density.

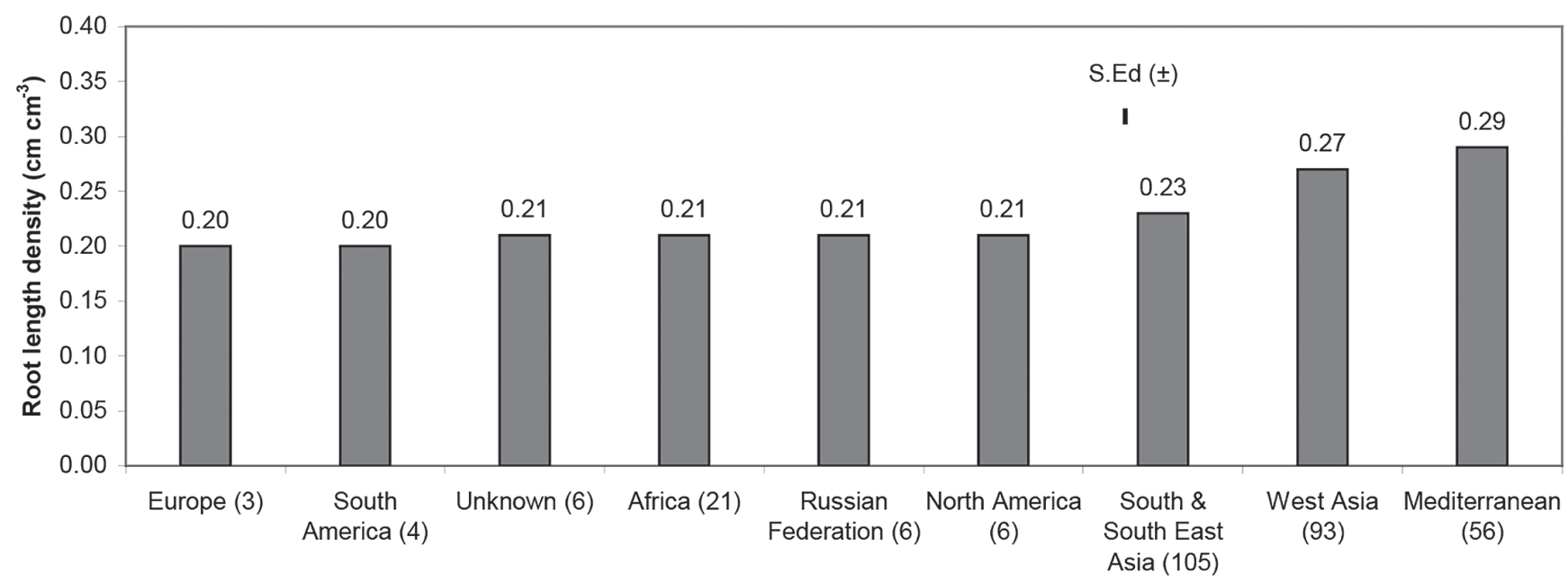

Geographical region

Figure 3. Graphical depiction of mean root-length densities of chickpea reference set accessions originating from different geographical regions.

$13.75 \mathrm{~cm}^{3}$ in 2007 (ICC 4958, $8.54 \pm 2.52$ ) and 41 with a volume of 13.91 to $15.85 \mathrm{~cm}^{3}$ in 2008 were better than ICC 4958 (11.51 \pm 2.34). Overall, accessions ICC 8261, ICC 18912, ICC 14446, ICC 15518, ICC 18679, ICC 20263, ICC 19122, ICC 15406, ICC 19226, ICC 3410, ICC 5337, ICC 20267, ICC 1422, ICC 10885, ICC 15264, ICC 4853, ICC 18699, ICC 10945, ICC 7255, ICC 15762 , ICC 18983, ICC 8740, and ICC 11498 were observed to be consistently and collectively best for all the root and shoot traits in both the years (Table 3). The 10 accessions that were poor in performance collectively for all the traits in both the seasons were ICC 12299, ICC 2507, ICC 9590, ICC 7323, ICC 11121, ICC 11279, ICC 4657, ICC 10018, ICC 4533, and ICC 1052, with their lowest values presented in Table 4. These contrasting germplasm lines can be useful in developing biparental mapping populations to develop multiparent, advanced-generation intercross populations to map QTLs. These genetically diverse and agronomically desirable accessions can make ideal source material for breeding drought-tolerant chickpea suitable for various agroecological regions across the world.

\section{DISCUSSION}

The results supported the initial expectation that the genotypes originating from different environments with contrasting seasonal variability will display morphophysiological differences associated with root traits (Purushothaman et al., 2014). Most root traits seem to express these differences, and the high level of success in the ongoing efforts to develop varieties with a vigorous and deeper root system to improve drought tolerance support this view (Varshney et al., 2014). Detailed analysis of phenotyping data on seven root traits indicated that the phenotypic variation in the reference set of chickpea germplasm was wider for all the root traits than earlier studies either with a chickpea recombinant inbred line mapping population in a Vertisol field (Serraj et al., 2004) or with the mini core chickpea germplasm assessed in PVC 
Table 3. List of 23 superior accessions that are consistently better in performance for most of the traits than the control cultivar (ICC 4958) with the relevant mean values for various traits in both the years and their geographical origin.

\begin{tabular}{|c|c|c|c|c|c|c|}
\hline ICC no. & $\begin{array}{c}\text { Shoot } \\
\text { dry weight }\end{array}$ & $\begin{array}{c}\text { Root } \\
\text { dry weight }\end{array}$ & $\begin{array}{l}\text { Rooting } \\
\text { depth }\end{array}$ & $\begin{array}{l}\text { Total-plant } \\
\text { dry weight }\end{array}$ & $\begin{array}{l}\text { Root-length } \\
\text { density }\end{array}$ & Geographical origin \\
\hline & \multicolumn{2}{|c|}{$\mathrm{g}$} & $\mathrm{cm}$ & $g$ & $\mathrm{~cm} \mathrm{~cm}^{-3}$ & \\
\hline ICC 8261 & 2.28 & 0.71 & 122.0 & 3.06 & 0.29 & Mediterranean \\
\hline ICC18912 & 2.30 & 0.80 & 128.0 & 3.08 & 0.29 & Mediterranean \\
\hline ICC 14446 & 2.36 & 0.72 & 127.9 & 3.10 & 0.28 & Mediterranean \\
\hline ICC 15518 & 2.68 & 0.74 & 136.4 & 3.44 & 0.27 & Mediterranean \\
\hline ICC18679 & 2.43 & 0.70 & 128.9 & 3.14 & 0.27 & Western Asia \\
\hline ICC19122 & 2.07 & 0.65 & 128.9 & 2.73 & 0.26 & Mediterranean \\
\hline ICC20263 & 2.42 & 0.70 & 130.0 & 3.14 & 0.26 & Western Asia \\
\hline ICC 15406 & 2.60 & 0.73 & 126.4 & 3.36 & 0.25 & Mediterranean \\
\hline ICC19226 & 1.97 & 0.75 & 121.0 & 2.65 & 0.25 & Mediterranean \\
\hline ICC 3410 & 1.87 & 0.71 & 131.5 & 2.51 & 0.24 & Western Asia \\
\hline ICC 5337 & 2.06 & 0.72 & 129.3 & 2.72 & 0.23 & Southern and Southeast Asia \\
\hline ICC 20267 & 2.18 & 0.80 & 120.9 & 2.98 & 0.22 & Southern and Southeast Asia \\
\hline ICC 1422 & 1.98 & 0.61 & 128.3 & 2.50 & 0.22 & Southern and Southeast Asia \\
\hline ICC 10885 & 2.24 & 0.90 & 137.4 & 3.15 & 0.22 & Africa \\
\hline ICC 15264 & 2.24 & 0.70 & 122.8 & 2.94 & 0.22 & Western Asia \\
\hline ICC 4853 & 1.96 & 0.62 & 125.1 & 2.53 & 0.22 & Unknown \\
\hline ICC18699 & 2.32 & 0.73 & 121.4 & 3.07 & 0.22 & Mediterranean \\
\hline ICC 10945 & 1.91 & 0.60 & 121.5 & 2.51 & 0.22 & Southern and Southeast Asia \\
\hline ICC 7255 & 2.10 & 0.73 & 122.4 & 2.78 & 0.22 & Southern and Southeast Asia \\
\hline ICC 15762 & 2.28 & 0.71 & 129.2 & 2.94 & 0.22 & Mediterranean \\
\hline ICC18983 & 2.27 & 0.70 & 138.5 & 3.03 & 0.22 & Mediterranean \\
\hline ICC 8740 & 1.94 & 0.73 & 141.2 & 2.61 & 0.22 & Western Asia \\
\hline ICC 11498 & 1.95 & 0.62 & 140.0 & 2.58 & 0.22 & Southern and Southeast Asia \\
\hline ICC 4958 (control) & 1.69 & 0.55 & 109.8 & 2.20 & 0.21 & Southern and Southeast Asia \\
\hline Trial mean & 1.77 & 0.59 & 107.71 & 2.36 & 0.20 & \\
\hline $\mathrm{LSD}^{+}(5 \%)$ & 0.34 & 0.14 & 10.84 & 0.43 & 0.04 & \\
\hline $\mathrm{SE}^{\dagger} \pm$ & 0.12 & 0.05 & 3.90 & 0.15 & 0.01 & \\
\hline $\mathrm{CV}^{+}(\%)$ & 18.90 & 25.31 & 12.20 & 17.82 & 22.48 & \\
\hline
\end{tabular}

†SE, standard error; LSD, least significant difference; CV, coefficient of variation.

Table 4. List of 10 accessions that are poor in performance consistently across the years for various root traits in chickpea reference set.

\begin{tabular}{|c|c|c|c|c|c|c|}
\hline ICC no. & $\begin{array}{c}\text { Shoot } \\
\text { dry } \\
\text { weight }\end{array}$ & $\begin{array}{c}\text { Root } \\
\text { dry } \\
\text { weight }\end{array}$ & $\begin{array}{l}\text { Rooting } \\
\text { depth }\end{array}$ & $\begin{array}{l}\text { Root- } \\
\text { length } \\
\text { density }\end{array}$ & $\begin{array}{c}\text { Root } \\
\text { surface } \\
\text { area }\end{array}$ & $\begin{array}{c}\text { Root } \\
\text { volume }\end{array}$ \\
\hline & 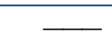 & $g-$ & $\mathrm{cm}$ & $\mathrm{cm} \mathrm{cm}^{-3}$ & $\mathrm{~cm}^{2}$ & $\mathrm{~cm}^{3}$ \\
\hline ICC 12299 & 1.19 & 0.44 & 102.40 & 0.18 & 664.50 & 8.74 \\
\hline ICC 2507 & 1.26 & 0.42 & 102.50 & 0.17 & 599.70 & 7.53 \\
\hline ICC 9590 & 1.28 & 0.41 & 104.10 & 0.17 & 615.70 & 7.91 \\
\hline ICC 7323 & 1.37 & 0.50 & 99.70 & 0.17 & 616.20 & 8.22 \\
\hline ICC 11121 & 1.35 & 0.50 & 96.30 & 0.17 & 618.80 & 8.28 \\
\hline ICC 11279 & 1.25 & 0.50 & 99.20 & 0.17 & 645.40 & 8.66 \\
\hline ICC 4657 & 1.39 & 0.47 & 102.40 & 0.18 & 644.20 & 8.52 \\
\hline ICC 10018 & 1.33 & 0.48 & 101.80 & 0.18 & 664.50 & 8.74 \\
\hline ICC 4533 & 1.42 & 0.53 & 96.30 & 0.17 & 618.80 & 8.28 \\
\hline ICC 1052 & 1.36 & 0.47 & 102.40 & 0.18 & 616.00 & 7.88 \\
\hline $\begin{array}{r}\text { ICC } 4958 \\
\text { (control) }\end{array}$ & 1.69 & 0.55 & 109.8 & 0.21 & 791.30 & 9.63 \\
\hline Trial mean & 1.77 & 0.59 & 107.71 & 0.20 & 775.81 & 10.57 \\
\hline $\mathrm{LSD}^{+}(5 \%)$ & 0.34 & 0.14 & 10.84 & 0.04 & 152.8 & 2.46 \\
\hline $\mathrm{SE}^{\dagger} \pm$ & 0.12 & 0.05 & 3.90 & 0.01 & 69.88 & 1.24 \\
\hline $\mathrm{CV}^{+}(\%)$ & 18.90 & 25.31 & 12.20 & 22.48 & 29.26 & 36.91 \\
\hline
\end{tabular}

† SE, standard error; LSD, least significant difference; CV, coefficient of variation. cylinders (Kashiwagi et al., 2005). The $h^{2}$ for the six root traits ranged from 0.32 to 0.70 and the root dry weight has shown the highest $h^{2}$ value, while the root depth the lowest. However, fixing the low-heritability traits in breeding may involve selections at a later filial generation and from a larger population (Kell, 2011; Comas et al., 2013). Root-length density, with its moderate $h^{2}$, is an important parameter in explaining crop growth and in evaluating advantages of root strength in crop water and nutrient uptake. As reported earlier (Kashiwagi et al., 2005), presence of higher mean root-length density at 45to $60-\mathrm{cm}$ depth in some accessions compared with the upper soil profiles has been the indication that there are useful accessions that have high potential for exploiting greater quantum of soil water from deeper horizons and avoid drought stress. Therefore, breeding for root-length density can be relatively easy (Krishnamurthy et al., 1999; Kashiwagi et al., 2005, 2015), whereas the inconsistency in rooting depth can pose difficulties to breed for, though the importance of this trait cannot be overlooked (Kashiwagi et al., 2015). This trait has been shown to be associated with terminal drought tolerance in chickpea (Kashiwagi 
et al., 2005). To describe rooting depth further, a deeper root system in practice means greater root-length density in deeper soil layers, and this trait has been recognized as a key target trait for enhancing drought tolerance (Gowda et al., 2011). The importance of greater root-length density for accessing greater quantity of soil water in dry soils by improving the number of contact points between roots and soil and in reducing the impact of soil resistance to the flow of water toward the root has been well documented (Passioura, 1983; Lynch, 2007; Blum, 2011).

Results from this study also suggest that there are accessions that possess greater root-length densities at soil depths below $60 \mathrm{~cm}$. The characteristic of receding soil moisture environment experienced under terminal drought is the constant increase in demand for soil water, while there is a constant decrease in supply and a constant shifting of the supply zone to deeper layers (Purushothaman et al., 2014; Kashiwagi et al., 2015). Greater root proliferation at deeper soil layers means greater support for the seed filling and greater grain yield formation with improved harvest indices under drought (Comas et al., 2013). Therefore, selection for greater root proliferation at depth with high $h^{2}$ can be expected to help enhancing the genetic gains and yield improvement in chickpea breeding efforts. In chickpea and peanut (Arachis hypogaea L.), the development of a larger proportion of the root structure at depth has been shown to contribute to higher grain yield (Jongrungklang et al., 2011; Zaman-Allah et al., 2011). Also, it has been shown that genotypes with higher preflowering root-length density in deeper soil layers possess enhanced drought tolerance with higher pod yield and harvest index under drought (Jongrungklang et al., 2013).

The accessions in this reference set varied extensively for the maximum rooting depth from 85.50 to 146.02 $\mathrm{cm}$. Genotypes with the capacity to develop deeper and well-branched lateral roots are considered advantageous in adapting to subsoil compaction or receding soil water environments in relation to capturing water from subsoil reserves (Kell, 2011; Comas et al., 2013). In chickpea, rooting depth is one among the main drought tolerance traits that play a key role for seed yield under terminal drought environments (Kumar et al., 2007). Also the benefit of deeper root systems has been shown in other studies (Kell, 2011). Root dry weight also exhibited large variation that ranged from 0.39 to $0.89 \mathrm{~g}$ with a high level $(0.52-0.70)$ of $h^{2}$. Root biomass is also a parallel measure to root-length density and has been shown to be positively associated with drought tolerance (Kashiwagi et al., 2006; Krishnamurthy et al., 1996). Shoot dry weight had the highest $h^{2}(0.69-$ 0.74) among the traits measured in the reference set of chickpea germplasm, as previously reported (Serraj et al., 2004; Kashiwagi et al., 2006). A close linear relationship was observed between the root dry weight and the shoot dry weight at 35 DAS. A high ratio of deep root weight to shoot weight was found to be important to maintain higher plant water potential and a have a positive effect on yield under stress (Krishnamurthy et al., 2013a).

Root/total-plant dry-weight ratio, with a $h^{2}$ of 0.54 in 2008 , showed a large genotypic variability ranging from 20.90 to 35.05 . This ratio is known to reduce with the increase in plant age as a consequence of relatively higher dry matter partitioning to the shoots (Krishnamurthy et al., 1996; Kashiwagi et al., 2005). Shoot-dry-weight/rootlength density ratio exhibited a moderate level of $h^{2}(0.43)$, with a large range of variation, from 8.5 to $14.3 \mathrm{~g} \mathrm{~cm} \mathrm{~cm}^{-3}$. The decreased $h^{2}$ values for this ratio with increasing soil depth is likely due to variation in drought severity across experiments that would result in differential induction of deep proliferation (Kijoji et al., 2013). Thus, rooting depth, root biomass, and root-length density were identified as the most promising traits in chickpea for terminal drought tolerance, as these help in greater extraction of soil moisture (Kashiwagi et al., 2006). The excellent consistency of root traits, demonstrated genetic variability, and its well-known relevance in enhancing drought tolerance has led to root traits being increasingly exploited in crop improvement programs. Importance of such root traits contributing to drought tolerance has also been demonstrated in other legumes (Wang et al., 2004). Nevertheless, progress made in assessing the genetic variability and exploiting root traits for crop improvement has still been painfully slow mainly due to the inherent difficulty in its accurate and high throughput phenotyping (Gowda et al., 2011; Jung and McCouch, 2013; Sheshshayee et al., 2013).

With the root system being a hidden, difficult-tomeasure organ, the possibilities of prediction through shoot system becomes highly desirable. Root volume and rooting depth were positively but only sparsely associated with the shoot dry weight in both the years, indicating that the expression of these two root traits were more independent of shoot system. Among all the root traits, root-length density was the highly and positively associated trait with the shoot dry weight offering a good level of confidence for prediction. The root/total-plant dry-weight ratio was correlated relatively close with the root dry weight than with the shoot dry weight, indicating that this ratio is dependent relatively more on root than the shoot performance.

The accessions originating from the Mediterranean region and western Asia have been found to possess the superior root-length densities along with greater shoot, root, and total-plant dry weights. Growth conditions for chickpea in the Mediterranean and western Asia are much drier than other regions but have a higher frequency of rainfall in the early stages of crop growth. Chickpea landraces evolving in those areas, therefore, may have adapted by increasing their root-length density as a way to capture more water.

In relatively lighter soils, these characteristics are much more relevant for better adaptation so as to rapidly 
extract maximum soil water that is available in early stages of crop growth and can be quickly lost at the reproductive stage. However, these traits cannot be of any advantage in environments supporting longer growth durations (Serraj et al., 2004; Kashiwagi et al., 2005). Characterization of the chickpea reference set helps breeders to use genetic resources for cultivar development more effectively because of the reduction in size of $(n=300)$ accessions to be evaluated while capturing the genetic diversity of the whole chickpea germplasm collection conserved at ICRISAT and ICARDA. Also, the chickpea reference set is known to be the potential reservoir of novel alleles for crop improvement that also possesses a good amount of diversity for important agronomic traits (Upadhyaya et al., 2008). This study provided evidence for the presence of a high level of genetic diversity in the chickpea reference set for the root traits. Root traits are difficult to study, and this experiment documents the extent of variation in seven root-related traits. Growth rates and productivity under water-limited conditions can be improved only when the most relevant drought tolerance traits are identified and brought under a single genetic background.

With a better understanding of root traits and their genetics, further improvement in root systems is possible by using the diversity currently found within modern cultivated germplasm (Blum, 2011). This reference set is manageable in size, so it has been extensively evaluated under replicated multienvironments for various economically important traits of interest (Lalitha, 2012). Of the 23 accessions that were found to be best for root traits in reference set, some were also found to be superior in many other abiotic, biotic, and agronomic traits, as already reported (Upadhyaya et al., 2013). ICC 8261, which is found to be superior for root-length density, was earlier reported as the best drought and salinity resistant accession with a higher 100-seed weight (30-38 g) than L $550(20 \mathrm{~g})$ and resistant to Botrytis gray mold (BGM). Likewise, ICC 5337 combines high $\delta^{13} \mathrm{C}$, transpiration efficiency, and root-length density, conferring resistance to drought. ICC 15406 is also confirmed to be resistant to BGM and legume pod borer, also with a greater 100-seed weight (29-43 g) than L 550 (20 g). ICC 7255, ICC 8740, ICC 10885, ICC 15518, and ICC 15264 were reported as moderately resistant to BGM (Pande et al., 2006). ICC 1422 and ICC 14446 were found to be resistant to drought (Upadhyaya et al., 2013). ICC 3410 and ICC 4853 were reported to be salinity resistant (Krishnamurthy et al., 2011). These accessions are a rich source of multiple resistances to various biotic and abiotic stresses, confirming the usefulness of this reference set of chickpea germplasm with good agronomic and physiological values.

\section{CONCLUSIONS}

A large genetic variability for all the root traits was observed among the reference set of chickpea germplasm accessions. These results matched well with the previous evaluations using the mini core collection of chickpea germplasm and the performance of ICC 4958, an accession used as control in both the studies. The root and the shoot dry weight showed high heritability and variation, while other traits exhibited a wide variation and moderate levels of heritability. The accessions originating from the Mediterranean region and western Asia possessed the best root-length densities, indicating potential for further selection from these regions. This study has identified new sources of germplasm that would augment the existing list of drought-avoidance chickpea germplasm.

\section{Acknowledgments}

The technical support of Mr. Md. Yusuf, Tirupathi Reddy and J. Shankaraiah during the cylinders experiment is gratefully acknowledged.

\section{References}

Ahmad, F., P.M. Gaur, and J. Croser. 2005. Chickpea (Cicer arietinum L.). In: R. Singh and P. Jauhar, editors, Genetic resources, chromosome engineering and crop improvement: Grain legumes. CRC Press, Boca Raton, FL. p. 185-214.

Blum, A. 2011. Plant breeding for water-limited environments. Springer Science Business Media, New York. doi: 10.1007/9781-4419-7491-4

Comas, L.H., S.R. Becker, V.M.V. Cruz, P.F. Byrne, and D.A. Dierig. 2013. Root traits contributing to plant productivity under drought. Front. Plant Sci. 4(442):1-16.

Dua, R.P., S.K. Chaturvedi, and S. Sewak. 2001. Reference varieties of chickpea for IPR regime. Ind. Inst. Pulse Res, Kanpur, India. p. 34.

FAOSTAT. 2013. Statistical database 2013. http://faostat.fao.org/ site/567/DesktopDefault.aspx?PageID=567\#ancor (accessed 20 Nov. 2014).

Glaszmann, J.C., B. Kilian, H.D. Upadhyaya, and R.K. Varshney. 2010. Accessing genetic diversity for crop improvement. Curr. Opin. Plant Biol. 13:167-173. doi:10.1016/j.pbi.2010.01.004

Gowda, C.L.L., O. Singh, S.C. Sethi, K.B. Singh, B.V. Rao, M.M. Rahman, Jagdish Kumar, and A. Rahman. 1995. Registration of 'ICCV 10' chickpea. Crop Sci. 35:588. doi:10.2135/cropsci1995. 0011183X003500020054x

Gowda, V.R.P., A. Henry, A. Yamauchi, H.E. Shashidhar, and R. Serraj. 2011. Root biology and genetic improvement for drought avoidance in rice. Field Crops Res. 122:1-13. doi:10.1016/j. fcr.2011.03.001

Jongrungklang, N., B. Toomsan, N. Vorasoot, S. Jogloy, K.J. Bonte, G.T. Hoogenboom, and A. Patanothai. 2011. Rooting traits of peanut genotypes with different yield responses to pre-flowering drought stress. Field Crops Res. 120:262-270. doi:10.1016/j. fcr.2010.10.008 
Jongrungklang, N., B. Toomsan, N. Vorasoot, S. Jogloy, K.J. Boote, G.T. Hoogenboom, and A. Patanothai. 2013. Drought tolerance mechanisms for yield responses to pre-flowering drought stress of peanut genotypes with different drought tolerant levels. Field Crops Res. 144:34-42. doi:10.1016/j.fcr.2012.12.017

Jukanti, A.K., P.M. Gaur, C.L.L. Gowda, and R.N. Chibbar. 2012. Nutritional quality and health benefits of chickpea (Cicer arietinum L.): A review. Br. J. Nutr. 108:S11-S16. doi:10.1017/ S0007114512000797

Jung, J.K., and S.R. McCouch. 2013. Getting to the roots of it: Genetic and hormonal control of root architecture. Front. Plant Sci. 4:1-32. doi:10.3389/fpls.2013.00186

Kashiwagi, J., L. Krishnamurthy, J.H. Crouch, and R. Serraj. 2006. Variability of root characteristics during vegetative stage and relationship with seed yield in chickpea genotypes (Cicer arietinum L). Field Crops Res. 95:171-181. doi:10.1016/j.fcr.2005.02.012

Kashiwagi, J., L. Krishnamurthy, R. Purushothaman, H.D. Upadhyaya, P.M. Gaur, C.L.L. Gowda, O. Ito, and R.K. Varshney. 2015. Scope for improvement of yield under drought through the root traits in chickpea (Cicer arietinum L). Field Crops Res. 170:47-54. doi:10.1016/j.fcr.2014.10.003

Kashiwagi, J., L. Krishnamurthy, H.D. Upadhyaya, and P.M. Gaur. 2008. Rapid screening technique for canopy temperature status and its relevance to drought tolerance improvement in chickpea. J. SAT Agric. Res. 6:1-4.

Kashiwagi, J., L. Krishnamurthy, H.D. Upadhyaya, H. Krishna, S. Chandra, V. Vadez, and R. Serraj. 2005. Genetic variability of drought-avoidance root traits in the mini-core germplasm collection of chickpea (Cicer arietinum L.). Euphytica 146:213-222. doi:10.1007/s10681-005-9007-1

Kell, D.B. 2011. Breeding crop plants with deep roots: Their role in sustainable carbon, nutrient and water sequestration. Ann. Bot. (Lond.) 108:407-418. doi:10.1093/aob/mcr175

Kijoji, A.A., S. Nchimbi-Msolla, Z.L. Kanyela, S.P. Klassen, R. Serraj, and A. Henry. 2013. Water extraction and root traits in Oryza sativa $\times$ Oryza glaberrima introgression lines under different soil moisture regimes. Funct. Plant Biol. 40:54-66. doi:10.1071/ FP12163

Krishnamurthy, L., C. Johansen, and O. Ito. 1996. Genetic variation in root system development and its implications for drought resistance in chickpea. In: O. Ito, C. Johansen, J.J. Adu-Gyamfi, K. Katayama, J.V.D.K. Kumar Rao, and T.J. Rego, editors, Root and nitrogen in cropping systems of the semi-arid tropics. Culio Corp., Tsukuba. p. 234-250.

Krishnamurthy, L., C. Johansen, and S.C. Sethi. 1999. Investigation of factors determining genotypic differences in seed yield of nonirrigated and irrigated chickpea using a physiological model of yield determination. J. Agron. Crop Sci. 183:9-17. doi:10.1046/ j.1439-037x.1999.00306.x

Krishnamurthy, L., J. Kashiwagi, P.M. Gaur, H.D. Upadhyaya, and V. Vadez. 2010. Sources of tolerance to terminal drought in the chickpea (Cicer arietinum L.) minicore germplasm. Field Crops Res. 119:322-330. doi:10.1016/j.fcr.2010.08.002

Krishnamurthy, L., J. Kashiwagi, S. Tobita, I. Osamu, H.D. Upadhyaya, C.L.L. Gowda, P.M. Gaur, M.S. Sheshshayee, S. Singh, V. Vadez, and R.K. Varshney. 2013a. Variation in carbon isotope discrimination and its relationship with harvest index in the reference collection of chickpea germplasm. Funct. Plant Biol. 40:1350-1361. doi:10.1071/FP13088
Krishnamurthy, L., J. Kashiwagi, H.D. Upadhyaya, C.L.L. Gowda, P.M. Gaur, S. Singh, R. Purushothaman, and R.K. Varshney. 2013b. Partitioning coefficient- a trait that contributes to drought tolerance in chickpea. Field Crops Res. 149:354-365. doi:10.1016/j.fcr.2013.05.022

Krishnamurthy, L., N.C. Turner, P.M. Gaur, H.D. Upadhyaya, R.K. Varshney, K.H.M. Siddique, and V. Vadez. 2011. Consistent variation across soil types in salinity resistance of a diverse range of chickpea (Cicer arietinum L.) genotypes. J. Agron. Crop Sci. 197:214-227. doi:10.1111/j.1439-037X.2010.00456.x

Kumar, J., and S. Abbo. 2001. Genetics of flowering time in chickpea and its bearing on productivity in semiarid environments. Adv. Agron. 72:107-138.

Kumar, N., A.S. Nandwal, R.S. Waldia, and R.K. Pannu. 2007. Root growth of chickpea genotypes in relation to drought tolerance. In: D.P. Singh, V.S. Tomar, R.K. Behl, S.D. Upadhyaya, M.S. Bhale, and D. Hare, editors, Sustainable crop production in stress environments: Management and genetic options. Jawaharlal Nehru Krishi Vishwa Vidyalaya, Jabalpur, Madhya Pradesh. p. 133-138.

Kutschera, L., E. Lichtenegger, and M. Sobotik. 2009. Wurzelatlas der Kulturpflanzen gema Bigter Gebiete mit Arten des Feldgemusebaues. Frankfurt/Main, DLG Verlag.

Lalitha, N. 2012. Genotypic and phenotypic diversity in chickpea (Cicer arietinum L.) reference set. $\mathrm{PhD}$ thesis. ICRISAT, Patancheru, India. http://oar.icrisat.org/id/eprint/6580

Ludlow, M.M., and R.C. Muchow. 1990. Critical evaluation of traits for improving crop yields in water-limited environments. In: N.C. Brady, editor, Advances in agronomy 43. Academic Press, New York. p. 107-153.

Lynch, J.P. 2007. Roots of the second green revolution. Aust. J. Bot. 55:493-512. doi:10.1071/BT06118

Lynch, J.P. 2013. Steep, cheap and deep: An ideotype to optimize water and an acquisition by maize root systems. Ann. Bot. (Lond.) 112:347-357. doi:10.1093/aob/mcs293

Pande, S., G.K. Kishore, H.D. Upadhyaya, and J.N. Rao. 2006. Identification of sources of multiple disease resistance in minicore collection of chickpea. Plant Dis. 90:1214-1218.

Passioura, J.B. 1983. Roots and drought resistance. Agric. Water. Manage. 7:265-280.

Patterson, H.D., and R. Thompson. 1971. Recovery of interblock information when block sizes are unequal. Biometrika 58:545554. doi:10.1093/biomet/58.3.545

Purushothaman, R., H.D. Upadhyaya, P.M. Gaur, C.L.L. Gowda, and L. Krishnamurthy. 2014. Kabuli and desi chickpeas differ in their requirement for reproductive duration. Field Crops Res. 163:24-31. doi:10.1016/j.fcr.2014.04.006

Saxena, M.C., and K.B. Singh. 1987. Chickpea breeding. In: M.C. Saxena and K.B. Singh, editors, The chickpea. CAB International, Wallingford, UK. p. 127-162.

Saxena, N.P., and C. Johansen. 1990. Functional ideotypes for increasing and stabilizing chickpea yield. In: Proceedings of The Fifth Australian Agronomy Conference, 24-29 Sept. 1989. The University of Western Australia, Perth, Western Australia. p. 657.

Serraj, R., F.R. Bidinger, Y.S. Chauhan, N. Seetharama, S.N. Nigam, and N.P. Saxena. 2003. Management of drought in ICRISAT cereal and legume mandate crops. In: J.W. Kijne, R. Barkar, and D. Molden, editors, Water productivity in Agriculture: Limits and opportunities for improvement. CABI, Wallingford, UK. p. 127-144. 
Serraj, R., L. Krishnamurthy, J. Kashiwagi, J. Kumar, S. Chandra, and J.H. Crouch. 2004. Variation in root traits of chickpea (Cicer arietinum L.) grown under terminal drought. Field Crops Res. 88:115-127. doi:10.1016/j.fcr.2003.12.001

Serraj, R., and T.R. Sinclair. 2002. Osmolyte accumulation: Can it really help increase crop yield under drought conditions? Plant Cell Environ. 25:335-341. doi:10.1046/j.13653040.2002.00754.x

Sheshshayee, M.S., M.V. Mohan Kumar, B.R. Raju, M.D. Pratibha, M.P. Rajanna, B. Mohanraju, and M. Udayakumar. 2013. Enhancing water use efficiency besides effective use of water is a potential strategy in developing rice cultivars suitable for semiirrigated aerobic cultivation. In: K. Muralidharan and E.A. Siddiqe, editors, International dialogue on perception and prospects of designer rice. Society for Advancement of Rice Research, Directorate of Rice Research, Hyderabad, India. p. 261-272.

Singh, K.B., G. Bejiga, M.C. Saxena, and M. Singh. 1995. Transferability of chickpea selection indices from normal to droughtprone growing conditions in a Mediterranean environment. J. Agron. Crop Sci. 36:472-479.

Soltani, A., K. Ghassemi-Golezani, F.R. Khooje, and M. Moghaddam. 1999. A simple model for chickpea growth and yield. Field Crops Res. 62:213-224. doi:10.1016/S0378-4290(99)00017-9

Soltani, A., F.R. Khooie, K. Ghassemi-Golezani, and M. Moghaddam. 2000. Thresholds for chickpea leaf expansion and transpiration response to soil water deficit. Field Crops Res. 68:205-210. doi:10.1016/S0378-4290(00)00122-2

Turner, N.C., G.C. Wright, and K.H.M. Siddique. 2001. Adaptation of grain legumes (Pulses) to water limited Environments. Adv. Agron. 71:193-231.

Upadhyaya, H.D., N. Dronavalli, S.L. Dwivedi, J. Kashiwagi, L. Krishnamurthy, S. Pande, H.C. Sharma, V. Vadez, S. Singh, R.K. Varshney, and C.L.L. Gowda. 2013. Mini core collection as a resource to identifying new sources of variation for use in chickpea breeding and genomics. Crop Sci. 53:2506-2517. doi:10.2135/cropsci2013.04.0259

Upadhyaya, H.D., S.L. Dwivedi, M. Baum, R.K. Varshney, S.M. Udupa, C.L.L. Gowda, D. Hoisington, and S. Singh. 2008. Genetic structure, diversity, and allelic richness in composite collection and reference set in chickpea (Cicer arietinum L.). BMC Plant Biol. 8:106. doi:10.1186/1471-2229-8-106
Upadhyaya, H.D., B.J. Furman, S.L. Dwivedi, S.M. Udupa, C.L.L. Gowda, M. Baum, J.H. Crouch, H.K. Buhariwalla, and S. Singh. 2006. Development of a composite collection for mining germplasm possessing allelic variation for beneficial traits in chickpea. Plant. Genet. Resour. 4:13-19. doi:10.1079/PGR2005101

Upadhyaya, H.D., and R. Oritz. 2001. A mini core subset for capturing diversity and promoting utilization of chickpea genetic resources in crop improvement. Theor. Appl. Genet. 102:12921298. doi:10.1007/s00122-001-0556-y

van der Maesen, L.J.G. 1987. Origin, history and taxonomy of chickpea. In: M.C. Saxena and K.B. Singh, editors, The chickpea. CAB Int. Publ., UK. p. 11-34.

Varshney, R.K., M. Thudi, S.N. Nayak, P.M. Gaur, J. Kashiwagi, L. Krishnamurthy, D. Jaganathan, J. Koppulu, A. Bohra, S. Tripathi, A. Rathore, A.K. Jukanti, V. Jayalakshmi, A. Vemula, S. Singh, M. Yasin, M.S. Sheshshayee, and K.P. Viswanatha. 2014. Genetic dissection of drought tolerance in chickpea (Cicer arietinum L.). Theor. Appl. Genet. 127:445-462. doi:10.1007/s00122013-2230-6

VSN International. 2011. GenStat for Windows, 14.1 release. VSN International Ltd., Hemel Hempstead, UK.

Wald, A. 1943. Tests of statistical hypotheses concerning several parameters when the number of observations is large. Trans. Am. Math. Soc. 54:426-482. doi:10.1090/S0002-9947-19430012401-3

Wang, W., B. Vinocur, O. Shoseyov, and A. Altman. 2004. Role of plant heat-shock proteins and molecular chaperones in the abiotic stress response. Trends Plant Sci. 9:244-252. doi:10.1016/j. tplants.2004.03.006

Yusuf Ali, M., L. Krishnamurthy, N.P. Saxena, O.P. Rupela, J. Kumar, and C. Johansen. 2002. Scope for genetic manipulation of mineral acquisition in chickpea. Plant Soil 245:123-134. doi:10.1023/A:1020616818106

Zaman-Allah, M., D.M. Jenkinson, and V. Vadez. 2011. Chickpea genotypes contrasting for seed yield under terminal drought stress in the field differ for traits related to the control of water use. Funct. Plant Biol. 38:270-281. doi:10.1071/FP10244

Zope, W.N., K.B. Wanjari, J. Kumar, H.A. van Rheenen, and B.V. Rao. 2002. PKV Kabuli 2: An extra bold kabuli chickpea variety. ICPN 9:4-6. 